\title{
Autoantibodies to the islet antigen ICA69 occur in IDDM and in rheumatoid arthritis
}

\author{
S. Martin ${ }^{1}$, J. Kardorf $f^{1}$, B. Schulte ${ }^{1}$, E. F. Lampeter ${ }^{1}$, F. A. Gries ${ }^{1}$, I. Melchers ${ }^{2}$, R. Wagner ${ }^{3}$, J. Bertrams ${ }^{4}$, B. O. Roep ${ }^{5}$, \\ A. Pfïtzner ${ }^{6}$, M. Pietropaolo ${ }^{7}$, H. Kolb ${ }^{1}$ \\ ${ }^{1}$ Diabetes Research Institute at the Heinrich Heine-University Düsseldorf, Düsseldorf, Germany \\ ${ }^{2}$ Clinical Research Unit on Rheumatology, Albert-Ludwigs-University Freiburg, Freiburg, Germany \\ ${ }^{3}$ Department of Endocrinology, University Hospital Essen, Essen, Germany \\ ${ }^{4}$ Department of Laboratory Medicine and Microbiology, Elisabeth Hospital, Essen, Germany \\ ${ }^{5}$ Department of Immunohaematology and Blood Bank, University Hospital, Leiden, The Netherlands \\ ${ }^{6}$ Department of Endocrinology, Johannes-Gutenberg-Universität, Mainz, Germany \\ ${ }^{7}$ Barbara Davis Center for Childhood Diabetes, University of Colorado, Denver, USA
}

Summary Islet cell antigen (ICA) 69 is a newly-recognized islet cell antigen to which autoantibodies have been observed in prediabetic relatives of patients with insulin-dependent-diabetes mellitus (IDDM). Here we extend the earlier analysis of ICA 69 antibodies to patients with recent-onset IDDM and to patients with other immune-mediated diseases. ICA 69 antibodies were determined by Western blot using an affinity purified recombinant fusion protein of ICA 69 and maltose binding protein. ICA 69 antibody quantities were determined as titres using a titration curve of a standard serum as reference. Mean logarithmic ICA 69 antibody titres were $3.4( \pm 1.4)$ in 99 patients with acute IDDM compared to $2.8( \pm 0.9)$ in 49 healthy blood donors $(p<0.001)$. A higher mean ICA 69 antibody titre of $4.1( \pm 0.8)$ was observed in 16 patients with rheumatoid arthritis in comparison to acute IDDM $(p<0.01)$ and healthy control subjects $(p<0.001)$. The percentage of sera with ICA 69 antibody titres above the 2 SD level of normal subjects was $21 \%$ in
IDDM, $31 \%$ in rheumatoid arthritis and $6 \%$ in healthy blood donors. None of the patients with autoimmune thyroid disease $(n=20)$, inflammatory bowel disease $(n=9)$ or multiple sclerosis $(n=7)$ had elevated ICA 69 antibodies. In IDDM, presence of ICA 69 antibodies persisted and the titre remained the same over 18 months of follow-up. The relationship of ICA 69 antibodies to islet cell antibodies (ICA) or insulin autoantibodies (IAA) was tested. The production of ICA 69 antibodies was not associated in diabetic patients with the presence of any of the two other autoantibodies. In conclusion, this study describes ICA 69 antibodies in acute IDDM and finds them to be independent of other islet autoantibodies. In addition ICA 69 is a target of humoural autoimmunity not only in IDDM but also in rheumatoid arthritis. [Diabetologia (1995) 38: 351-355]

Key words ICA 69, insulin-dependent diabetes mellitus; rheumatoid arthritis.
The pathogenesis of insulin-dependent diabetes mellitus (IDDM) is characterized by a long subclinical period during which circulating autoantibodies to islet antigens are associated with the disease process

Received: 3 June 1994 and in revised form: 8 September 1994

Corresponding author: Dr. S. Martin, Diabetes Research Institute, Clinical Department, Auf'm Hennekamp 65, D-40225 Düsseldorf, Germany

Abbreviations: IDDM, Insulin-dependent diabetes mellitus; ICA, islet cell antibodies; IAA, insulin autoantibodies; RA, rheumatoid arthritis; RF, rheumatoid factor; GAD 65, glutamic acid decarboxylase; SMS, stiff-man syndrome. in pancreatic islets [1]. The prediction of later overt diabetes in relatives of IDDM patients and in the general population on the basis of the presence of islet cell antibodies (ICA) in serum has become a major field in diabetes research. To date, testing for ICA by an indirect immunofluorescence technique yields the best predictive values [2,3]. A growing number of islet autoantigens (insulin, glutamic acid decarboxylase (GAD 65), carboxypeptidase $\mathrm{H}$, glycolipids) has been described in recent years [4-8]. ICA 69 is the most recently identified islet autoantigen; it was isolated by immuno-screening of a human islet cell library [9] by islet cell antibody-positive pre-diabetic sera. In the initial report ICA 69 antibod- 
Table 1. Characteristics of patients and probands

\begin{tabular}{lrll}
\hline Group & $n$ & $\begin{array}{l}\text { Age } \\
\text { mean (range) }\end{array}$ & $\begin{array}{l}\text { Sex } \\
\text { (male/female) }\end{array}$ \\
\hline Control subjects & 49 & $28.2(18-70)$ & $30 / 19$ \\
IDDM & 99 & $18.8(0-54)$ & $57 / 42$ \\
RA & 16 & $56.5(32-78)$ & $3 / 13$ \\
Chronic autoimmune & 8 & $34.9(21-55)$ & $0 / 8$ \\
thyroiditis & & & \\
Graves' disease & 12 & $44.2(18-77)$ & $4 / 8$ \\
Ulcerative colitis & 5 & $33.0(19-51)$ & $5 / 0$ \\
Crohn's disease & 4 & $33.0(25-43)$ & $1 / 3$ \\
Multiple sclerosis & 7 & $33.8(23-46)$ & $4 / 3$ \\
\hline
\end{tabular}

Disease activities were determined by thyroglobulin antibody positivity for Graves' disease, clinical disease activity index (CDAI) greater than 150 for Crohn's disease, Truelove Index for ulcerative colitis, elevated sedimentation rate and C-reactive protein for RA in addition to typical clinical signs of the diseases

ies were determined in pre-clinical IDDM relatives known to have later developed overt disease and in healthy control subjects [9]. The present study extends the analysis of ICA 69 antibodies to patients with recent-onset IDDM and to patients with other immune-mediated diseases such as rheumatoid arthritis (RA), Crohn's disease, ulcerative colitis, multiple sclerosis and immune thyroid diseases. In addition to the analysis of disease specificity we analysed ICA 69 antibody persistence, age dependence and association with other autoantibodies.

\section{Subjects, materials and methods}

Patients. Serum samples were obtained from 99 recent-onset IDDM patients who were consecutive cases from the Clinical Department of the Diabetes Research Institute, Düsseldorf, Germany and the Department of Immunohaematology and Blood Bank, University Hospital, Leiden, The Netherlands. Sera of 49 blood donors were used as control samples. Furthermore, we tested sera of 16 patients with RA, fulfilling at least four of the 1987 revised American Rheumatism Association (ARA) criteria [10], obtained from the Clinical Research Unit on Rheumatology, Albert-Ludwigs-University Freiburg; seven patients with multiple sclerosis from the Department of Neurology, Julius-Maximilians-University, Würzburg (kindly provided by Dr. J.Zielasek); eight patients with chronic autoimmune thyroiditis, 12 patients with Graves' disease, five patients with ulcerative colitis and four patients with Crohn's disease from the Department of Endocrinology, University Hospital Essen. Characteristics of patients are described in Table 1.

ICA 69 production and purification. ICA 69 was expressed in the pMalc-expression vector [11] as fusion protein with maltose binding protein (ICA 69-Mbp) [9]. To control the specificity of autoantibodies to ICA 69 the fusion part Mbp was also expressed alone. Large-scale production and purification of ICA 69 or Mbp was performed by modification of a described previously procedure [12]: bacterial cells were harvested by centrifugation, lysates were prepared by standard procedure and purified by amylose affinity chromatography (New England Biolabs, Beverly, Mass., USA). Protein concentration was determined by spectrophotometry at $280 \mathrm{~nm}$ and purity was checked by SDS-PAGE, followed by silver staining and Western blotting using polyclonal anti-maltose-binding protein antibodies (New England Biolabs).

Antibody assays. Patient sera were tested by using a standardized Western blot assay. Five $\mu \mathrm{g}$ of ICA $69-\mathrm{Mbp}$ or $1.6 \mu \mathrm{g}$ of $\mathrm{Mbp}$ were subjected to $10 \%$ SDS-PAGE under reducing conditions and transferred onto nitrocellulose (Amersham Hybond, Braunschweig, Germany) by using a standard procedure $\left(200 \mathrm{~V}, 4^{\circ} \mathrm{C}, 1 \mathrm{~h}\right)$ using Miniprotein II cell (Biorad, München, Germany). The nitrocellulose was cut into strips and non-specific binding sites were blocked with non-fat dried milk ( $5 \%$ in PBS, $\mathrm{pH} 7.4$ ). Nitrocellulose strips were incubated with human sera or rabbit anti-Mbp polyclonal antibodies (overnight at $4^{\circ} \mathrm{C}$ ). Subsequently, nitrocellulose membranes were washed in phosphate buffered saline and incubated with polyclonal anti-human $\operatorname{IgG}$ or polyclonal anti-rabbit antibodies (Dako, Hamburg, Germany) directly conjugated to horseradish peroxidase $\left(24^{\circ} \mathrm{C}\right.$, $30 \mathrm{~min}$ ). Bound antibodies were detected by chloronaphthol staining. In each assay a standard high titre ICA 69 antibody-positive serum was run in three dilutions for calibration of the assay. All sera were initially tested at a 1:50 dilution and re-tested at higher dilutions where necessary. Serum reactivity with ICA 69 was expressed as endpoint titre using a logarithmic scale. Recombinant antigen and antibody assay are the same as described previously [9], except that ICA 69 antibody was not quantitated by densitometry but that antibody titres were determined. Coded sera tested in both assays showed comparable results, all positive sera were identified as positive in both assays and all negative sera as negative. Patient sera were not absorbed with $\mathrm{Mbp}$ since less than $25 \%$ of patients or control sera showed staining of $\mathrm{Mbp}$ in Western blot with mean titre below 2. Displacement studies showed that preincubation of a serum positive at a dilution of 1:500 with $5 \mu \mathrm{g}$ ICA 69 eliminated reactivity while preincubation with $13 \mu \mathrm{g} \mathrm{Mbp}$ did not block antibody binding. Twenty coded sera were tested twice in separate experiments resulting in a correlation coefficient of $r=0.89$ $(p<0.001)$ illustrating that antibody titres obtained with this assay are reproducible.

ICA were measured by indirect immunofluorescence on sections of fresh frozen human pancreas as described previously [13]. ICA titres were determined by endpoint titration using a standard of 80 JDF units. With an initial serum dilution of $1: 4$ the detection limit was 5 JDF units.

Insulin autoantibodies (IAA) were determined by RIA as described before [14]. Sera for LAA determinations were obtained prior to patients undergoing insulin therapy.

The presence of rheumatoid factors (RF) was ascertained by the latex and Waaler-Rose tests. RF positive $\left(\mathrm{RF}^{+}\right)$individuals were defined as having an RF value greater than 1:160 by the latex determination or a Waaler-Rose value greater than $1: 16$.

\section{Statistical analyses}

Student's $t$-test and Fisher's test were performed as appropriate to test for differences between groups with $p<0.05$ considered statistically significant. Lognormal distribution of antibody titres in healthy control subjects was confirmed by using Quickstat software package (CCP-Soft, Marburg, Germany). 


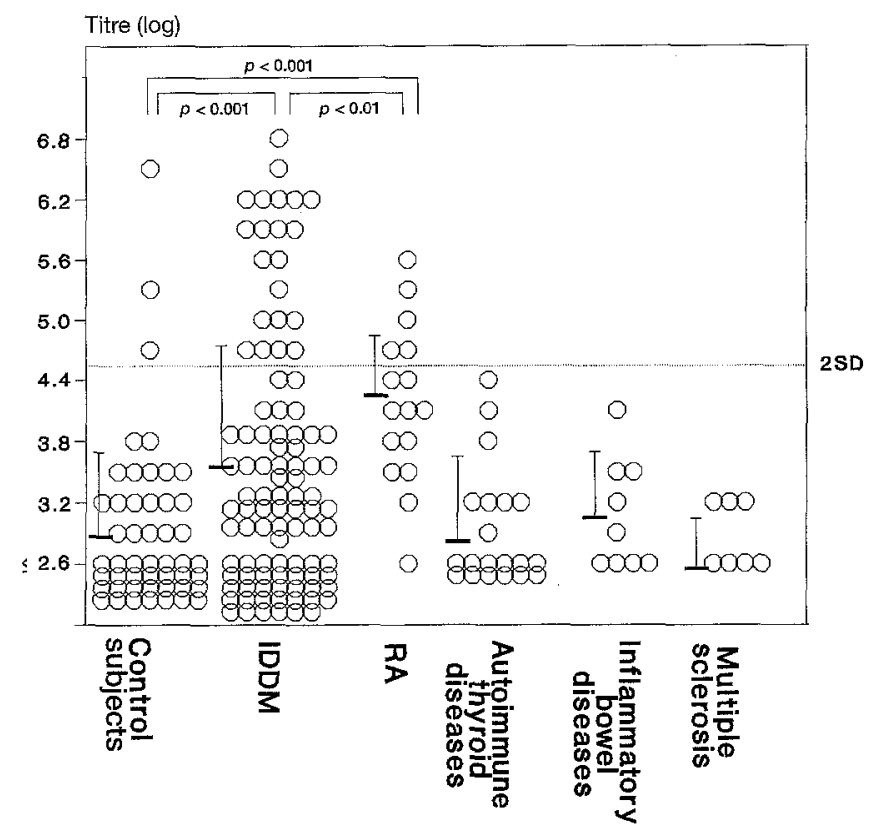

Fig. 1. Prevalence of ICA 69 autoantibodies in healthy control subjects $(n=49)$, recent-onset IDDM patients $(n=99)$, RA patients $(n=16)$, chronic autoimmune thyroiditis $(n=8)$, Graves' disease $(n=12)$, ulcerative colitis $(n=4)$, Crohn's disease $(n=5)$ and multiple sclerosis $(n=7)$. Bars representing mean logarithmic ICA 69 titre +1 SD. Statistical differences were calculated by Student's $t$-test for means and $\chi^{2}$ test

\section{Results}

The reactivity with ICA 69 of sera from 99 patients with recent IDDM, 16 patients with RA and 36 patients with other immune-mediated diseases (chronic autoimmune thyroiditis, multiple sclerosis, Graves' disease, colitis ulcerosa, Crohn's disease) in comparison to 49 healthy control subjects were tested in the standardized Western blot.

Serum reactivity to ICA 69 above the normal range (mean $\pm 2 \mathrm{SD}$ ) was detected in 21 out of 99
(21\%) IDDM sera and in 5 of $16(31 \%)$ RA sera compared to 3 of $49(6 \%)$ normal sera $(p<0.05$ and $p<0.01$, respectively). The mean titres of reactivity to ICA 69 were significantly elevated in IDDM sera $(3.4, p<0.001)$ and RA sera $(4.1, p<0.001)$ compared to 2.8 in normal sera (Fig. 1). However, the highest individual ICA 69 titres were observed in acute IDDM patients. Reactivity to ICA 69-Mbp was not elevated in sera from patients with chronic autoimmune thyroiditis, Graves' disease, ulcerative colitis, Crohn's disease or multiple sclerosis. Background reactivity to $\mathrm{Mbp}$ was similar in all cohorts with mean titre below 2 .

No correlation between "classic" islet cell antibodies (ICA) or insulin autoantibodies (IAA) and ICA 69 antibodies could been shown (Fig.2); i.e. ICA 69 antibodies were found to be either positive or negative for ICA or IAA. This implies that ICA 69 antibodies provide additional information compared to ICA and IAA.

In eight patients with ICA 69 antibody titres between 2 and over 4.7 at diabetes onset, follow-up studies were possible for 18 months. As shown in Figure 3 , levels of serum reactivity with ICA 69 remained remarkably constant throughout the observation period.

Since ICA 69 antibodies also occurred in patients with RA we analysed whether ICA 69 antibody positivity is linked to the presence of RF. All sera were tested in parallel for the presence of RF. High ICA 69 titres were detectable in patients both positive and negative for RF (data not shown).

\section{Discussion}

The recent identification of ICA 69 as a new member in the family of IDDM-associated autoantigens [9] has raised expectations for a better identification of

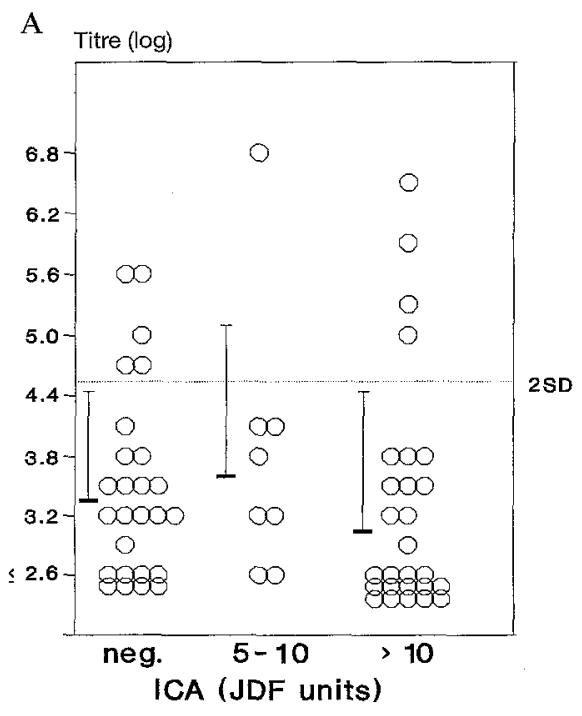

Fig. 2A,B. Lack of correlation of ICA (A) or IAA (B) and ICA 69 prevalence in recent-onset IDDM patients. Neg, ICA negative (detection limit 5 JDF units) 
Titre $(\log )$

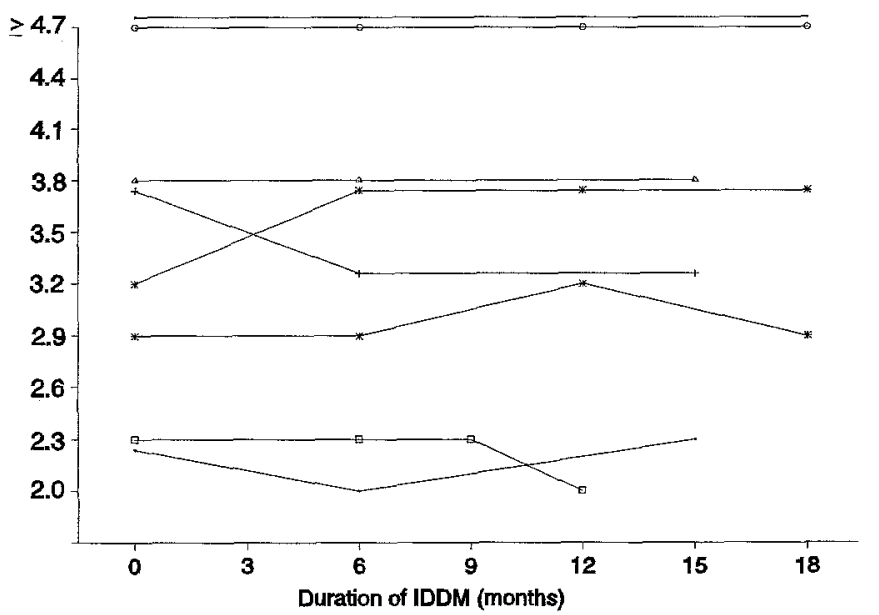

Fig.3. Follow-up of ICA 69 antibody titres in eight patients over a period of 18 months after diagnosis of IDDM

individuals at risk of developing the disease. We therefore tested the disease association of ICA 69 antibodies by comparing antibody reactivity in patients with recent-onset IDDM to patients with other immune-mediated diseases and to healthy control subjects. Recombinant antigen and Western blot antibody assay were essentially identical to an earlier study [9]. Coded sera with different titres were tested in both Western blot assays. All sera positive in our assay were identified as positive in the radioactive assay, the titres comparing both assays showing a strong correlation (data not shown).

The prevalence of ICA 69 antibody-positive sera (>2 SD) in acute-onset IDDM patients was 21 of 99 ( $21 \%)$ compared to 3 of 49 control subjects $(6 \%)$. In the earlier study 9 of 24 prediabetic relatives (38\%) and 2 of 70 healthy control subjects $(3 \%)$ had been found antibody positive. A larger number of prediabetic relatives will be needed to determine whether the prevalence of ICA 69 is indeed higher in prediabetic than in acute IDDM. Taken together, the data indicate that ICA 69 antibodies, as determined by Western blot techniques, have lower prevalence than ICA or GAD 65 antibodies in IDDM $[2,4,6]$.

With the present solid phase assay substantial background reactivity was seen with normal sera with a mean titre of 2.7. This reactivity was not caused by the Mbp part of the fusion protein since the mean reactivity to $\mathrm{Mbp}$ alone was below a titre of 2. This is also true for Mbp fused to an irrelevant protein (data not shown). A previous insulin autoantibody (IAA) standardization workshop has shown that even very high titres of IAA observed by solid phase assay (ELISA) were not recognizeable in a fluid phase assay (RIA) and hence represented lowaffinity antibodies [14-16]. We thus assume that an ICA 69 antibody assay which selects for high affinity antibodies will enlarge the difference in prevalence between patients and healthy blood donors. Such studies are currently in progress.

ICA 69 antibodies appeared in recent-onset IDDM patients independent of "classic" ICA, measured by indirect immunofluorescence or IAA measured by RIA. We conclude that there is no direct pathogenetic relationship between ICA 69 antibodies and the two other islet autoantibodies. Subanalysis of all tested IDDM patients showed that mean ICA 69 antibody titres showed no correlation with age or sex. Similar results have been reported for ICA, while a decrease of IAA prevalence with age has been observed [5, 13, 17]. Antibody titres of ICA 69 showed a remarkable persistence as shown in eight patients during 18 months of follow-up. Similar results have been reported for ICA in a comparable observation period. In conclusion, ICA 69 antibodies appear to be a marker for IDDM independent of ICA or IAA. Its usefulness for diagnostic purposes might be limited based on the relatively low percentage of $21 \%$ IDDM patients vs $6 \%$ healthy control subjects. However, a more stringent antibody detection assay may increase specificity and sensitivity.

When testing the disease association we surprisingly found high titres of ICA 69 antibodies also in RA patients. RA patients showed a higher mean titre and age than IDDM patients. However, healthy normal persons of similar age showed no elevated ICA 69 antibody titres (data not shown). ICA 69 antibodies were not elevated in autoimmune thyroid disease despite the known relationship to IDDM. Also, ICA69 antibody titres were in the normal range in other immune-mediated diseases like ulcerative colitis, Crohn's disease or multiple sclerosis. Because of the small size of patient cohorts tested the data are preliminary. However, it should be noted that of a total of 36 patients with diseases other than IDDM or RA none had ICA 69 antibody levels above the 2 SD level of normal compared to 5 of $16 \mathrm{RA}$ patients $(31 \%)(p<0.01)$. The prevalence of ICA 69 antibodies in these other autoimmune diseases ( 0 of 36$)$ was not significantly different from that in healthy control subjects (3 of 49). Expression of ICA69 transcripts outside islets has been shown in heart, brain, lung, liver and kidney but not in spleen, thymus, bowel, lymph nodes and salivary gland on the basis of Northern blot analysis [9]. The presence of ICA 69 antigen in synovium has not been tested. It is interesting to note that several target antigens of the autoimmune attack in IDDM also occur outside the islet such as glutamic acid decarboxylase and hsp65.

ICA 69 antibodies have been found in IDDM and RA. Occurrence of an IDDM-associated autoantibody in another disease has also been reported for the glutamic acid decarboxylase (GAD 65), a recently-identified diabetes-associated autoantigen [6]. Antibodies against GAD 65 can be seen in IDDM and in stiff-man syndrome (SMS), a rare neurological dis- 
ease. Interestingly, $34 \%$ of SMS patients develop IDDM [18] while no such correlation has been described for IDDM and RA [19].

The immunoreactive epitope in the ICA 69 molecule is unknown. In preliminary experiments we used an ICA 69-Mbp fusion protein lacking the Cterminal half (amino acid 203-483) of the ICA 69 molecule. The truncated protein showed no reactivity with sera containing ICA 69 antibodies, while it preserved reactivity with $\mathrm{Mbp}$ antibodies. Two short homologies to bovine serum albumin have been reported between amino acids 205-214 and 351-360 [9]. The lack of reactivity with the truncated ICA 69 molecule was seen independently of whether bovine milk proteins or ovalbumin was used for reduction of background signals in the Western blot. The identification of the immune reactive epitopes in IDDM and RA are of interest because antibody binding epitopes to GAD 65 in SMS have been shown to be different than in IDDM $[20,21]$. This observation implies that the immunoreactive regions are close to the C-terminal end of ICA 69. Further truncations are in preparation in order to identify the relevant epitopes and to compare recognition sites of autoantibodies from IDDM patients with RA and healthy control subjects.

Acknowledgements. We thank Dr. R. B. Elliott for help and critical discussion. This study was supported by Deutsche Forschungsgemeinschaft Grant MA1240/1-4 (S.M.), a grant from the Fritz-Thyssen Stiftung (S.M.) the Ministry for Science and Research of the State Nordrhein-Westfalen, Düsseldorf, and the Federal Ministry for Health, Bonn, Germany.

\section{References}

1. Eisenbarth GS (1986) Type 1 diabetes mellitus: a chronic autoimmune disease. N Engl J Med 314: 1360-1368

2. Bonifacio E, Bingley PJ, Shattock M et al. (1990) Quantification of islet-cell antibodies and prediction of insulin-dependent diabetes. Lancet 335: 147-149

3. Riley WJ, Maclaren NK, Krischer J et al. (1990) A prospective study of the development of diabetes in relatives of patients with insulin-dependent diabetes. N Engl J Med 323: 1167-1172

4. Bottazzo GF, Genovese S, Bosi E, Dean BM, Christie MR, Bonifacio E (1991) Novel considerations on the antibody/ autoantigen system in type 1 (insulin-dependent) diabetes mellitus. Ann Med 23: 453-461

5. Palmer JP, Asplin CM, Clemons P et al. (1983) Insulin antibodies in insulin-dependent diabetics before insulin treatment. Science 222: 1337-1339

6. Baekkeskov S, Aanstoot H, Christgau et al. (1990) Identification of the $64 \mathrm{~K}$ autoantigen in insulin-dependent diabetes as the GABA-synthesizing enzyme glutamic acid decarboxylase. Nature 347:151-156
7. Castano L, Russo E, Zhou L, Lipes MA, Eisenbarth GS (1991) Identification and cloning of a granule autoantigen (carboxypeptidase $\mathrm{H}$ ) associated with type 1 diabetes. J Clin Endocrinol Metab 73: 1197-1201

8. Dotta F, Colman PG, Lombardi D et al. (1989) Ganglioside expression in human pancreatic islets. Diabetes 38: 14781483

9. Pietropaolo M, Castano L, Babu et al. (1993) Islet cell autoantigen 69 (ICA 69): molecular cloning and characterization of a novel diabetes-associated autoantigen. J Clin Invest 92: 359-371

10. Arnett FC, Edworthy SM, Bloch DA et al. (1988) The American Rheumatism Association 1987 revised criteria for the classification of rheumatoid arthritis. Arthritis Rheum 31: 315-324

11. Riggs P (1990) Expression and purification of maltosebinding protein fusions. In: Ausubel FM, Brent R, Kingston RE et al. (eds) (1990) Current protocols in molecular biology. Greene Publishing Associates and Wiley Interscience, New York, 16.6.1-16.6.12

12. Martin S, Martin A, Staunton DE, Springer TA (1993) Functional studies of truncated soluble intercellular adhesion molecule 1 expressed in Escherichia coli. Antimicrob Agents Chemother 37: 1278-1285

13. Kolb H, Dannehl K, Grünklee D, Zielasek J, Bertrams J, Hübinger A, Gries FA (1988) Prospective analysis of islet cell antibodies in children with type 1 (insulin-dependent) diabetes. Diabetologia 31: 189-194

14. Ziegler AG, Ziegler R, Vardi P, Jackson RA, Soeldner JS, Eisenbarth GS (1989) Life-table analysis of progression to diabetes of anti-insulin autoantibody-positive relatives of individuals with type 1 diabetes. Diabetes 38: 1320-1325

15. Greenbaum C, Palmer JP, Kuglin B, Kolb H (1992) Insulin autoantibodies measured by RIA methodology are more related to IDDM than those measured by ELISA. J Clin Endocrinol Metab 74: 1040-1044

16. Kuglin B, Bertrams J, Linke C, Gries FA, Kolb H (1989) Prevalence of cytoplasmatic islet cell antibodies and insulin autoantibodies is increased in subjects with genetically defined high risk for insulin-dependent diabetes mellitus. Klin Wochenschr 67: 66-73

17. Arslainen SA, Becker DJ, Rabin B et al. (1985) Correlates of insulin antibodies in newly diagnosed children with insulin-dependent diabetes before insulin therapy, Diabetes 34 : 926-930

18. Solimena M, Folli F, Asparisi R, Pozza G, De Camilli P (1990) Autoantibodies to GABA-ergic neurons and pancreatic beta-cells in Stiff-man syndrome. $N$ Engl J Med 322: $1555-1560$

19. Hakala M, Ilonen J, Reijonen H, Knip M, Koivisto O, Isomaki H (1992) No association between rheumatoid arthritis and insulin dependent diabetes mellitus: an epidemiologic and immunogenetic study. J Rheumatol 19: 856-858

20. Solimena M, De Camilli P (1993) Spotlight on a neuronal enzyme. Nature 366: 15-17

21. Li LS, Hagopian WA, Brashear HR, Daniels T, Lernmark A (1994) Identification of autoantibody epitopes of glutamic acid decarboxylase in Stiff-man syndrome patients. J Immunol 152: 930-934 